http://jmscr.igmpublication.org/home/ ISSN (e)-2347-176x ISSN (p) 2455-0450

crossref DOI: https://dx.doi.org/10.18535/jmscr/v8i4.86

\author{
Dournal Of Medical Science And Clinical Research \\ IGM Publication \\ An Official Publication of IGM Publication
}

\title{
Significance of HER 2/neu in Gastric Adenocarcinomas, A Clinico- pathological correlation
}

\section{Dr Debahuti Mohapatra', Dr Kaushambi Chakraborty ${ }^{2 *}$, Dr Debasmita Das ${ }^{3}$, Dr Rupanita Biswal ${ }^{4}$}

${ }^{1}$ Professor \& Head of the Department, Department of Pathology, IMS \& SUM Hospital, Bhubaneswar

${ }^{2}$ Senior Resident, Department of Pathology, ESI-PGIMSR, Medical College \& Hospital, Joka, Kolkata

${ }^{3}$ Resident, Department of Pathology, IMS \& SUM Hospital, Bhubaneswar

${ }^{4}$ Assistant Professor, Department of Pathology, IMS \& SUM Hospital, Bhubaneswar

*Corresponding Author

Dr Kaushambi Chakraborty

\begin{abstract}
Background: Gastric cancers are the fifth most common cancer and the third most common cause of cancer mortality, in which adenocarcinoma tops the list. Human epidermal growth factor receptor 2 (Her2/neu), a proto-oncogene on amplification leads to various human cancers, namely breast, colon, cervical, endometrial, urothelial and recently discovered gastric adenocarcinoma.

Material and Methods: A prospective study was conducted in the Department of Pathology of a tertiary care hospital, Bhubaneswar, Odisha from January 2015 to December 2017. Endoscopic, total, distal and partial gastrectomy specimens were included after clinico-radiological data collection. The exclusion criterion was biopsies received post neo-adjuvant therapy.

Her2/neu immunohistochemistry (IHC) was conducted on all the adenocarcinoma of gastric/ gastroesophageal location and was scored as $0,1+, 2+$ and 3+ (absent, mild, moderate and strong positivity).

Observation: It was found that gastric antrum was the commonest location followed by body and gastroesophageal junction. According to histological types, classical intestinal type showed maximum Her2/neu positivity followed by papillary, signet ring cell type while diffuse type showed least positivity.Though most of the strong Her2/neu adenocarcinomas were well differentiated type but majority of them presented with lymphnode metastasis.

Conclusion: In developing countries, the mortality due to gastric adenocarcinoma is high. The study aims at the prevalence of Her2/neu positivity in various sites, types, grade and stage of gastric adenocarcinomas to facilitate the institution of targeted therapy (anti-Her2/neuAb, Transtuzumab) in order to see its effect on patients' morbidity and mortality.

Keywords: Gastric Adenocarcinoma, Her2/neu, Transtuzumab.
\end{abstract}

\section{Introduction}

Gastric cancer is the fifth most common cancer and the third most common cause of cancer related death worldwide. ${ }^{1}$ Human epidermal growth factor receptor 2 (HER2), also known as cerbB2is a proto-oncogene located on chromosome $17 \mathrm{q} 21$ that encodes a $180 \mathrm{kDa}$ transmembrane protein with tyrosine kinase activity, a member of 
the HER receptor family and is involved in signal transduction pathways, leading to cell growth and differentiation. ${ }^{2}$ The Her 2 proto-oncogene is unique because unlike other members of epidermal growth factor receptor family, it has no direct ligand. Amplification of the human epidermal growth factor receptor 2 (Her2/neu) gene and/or overexpression of the HER2 protein has been observed in many human carcinomas, including breast, colon, endometrial, cervical, urothelial, lung, ovarian and recently gastrointestinal adenocarcinoma.,

HER2 gene amplification and overexpression of its product were first discovered in breast cancer and are significantly associated with worse outcomes. ${ }^{2}$ In gastro-esophageal, gastric, small intestine and colorectal adenocarcinoma the frequency of $\mathrm{Her} 2 / \mathrm{neu}$ overexpression varies widely in the literature, studies have yielded inconsistent findings regarding its prognostic relevance. Unfortunately, conventional chemotherapeutic agents such as 5-fluorouracil, cisplatin, epirubicin and docetaxel have been of limited success and efforts have been focused in identifying better molecular targeted therapy.

Trastuzumab is a monoclonal antibody directed against Her2, as one the first molecular-targeted drugs to be developed; it was first introduced for the treatment of Her 2 positive advanced breast cancer. ${ }^{2}$ Trastuzumab prevents dimerization of Her2 with other HER family membranes and stimulating endocytosis, it seems to induce cell mediated immunity and inhibit angiogenesis.

Carcinomas of the gastro-esophageal junction may be either esophageal or gastric cardiac origin, and the most common clinical association is gastroesophageal reflux which contrast with the dietary and infection (H. Pylori) association of the carcinomas of the distal stomach. Recent studies have reported that the intestinal type of gastric carcinoma has higher prevalence of Her2 overexpression (16-34\%) compared to diffuse type (2-7\%). Mixed intestinal-diffuse type adenocarcinoma have Her2 overexpression, these tumors is limited to areas of intestinal-type histomorphology carrying higher rates of Her2 overexpression is also true for gastro-esophageal adenocarcinomas. Rarer histologic types of gastric adenocarcinomas require further study.

In the ToGA trial, patients with Her2-expressing gastroesophageal and gastric adenocarcinoma were treated with Trastuzumab and chemotherapy, showed statistically significant increase in overall survival. ${ }^{5}$ In the light of the aforementioned considerations, it is urgent for us to explore the possible differences of gene expression level and prognosis among various sites, types and grades of gastric adenocarcinomas. Knowledge of the molecular differences would help us to improve the prognostication and treatment strategy in clinical practice.

\section{Aims and Objectives}

1. To study the incidence of gastric adenocarcinoma according to age, location and types.

2. The prevalence of Her2/neu positivity in various types, sites, grade and stage of gastric adenocarcinoma.

3. Follow-up of these patients to know the effectiveness of Trastuzumab therapy in primary and metastatic disease.

\section{Material \& Methods}

Study Population- This prospective study was conducted in the Department of Pathology of a tertiary care hospital of Bhubaneswar, Odisha from January 2015 to December 2017. Both endoscopicand total, distal and partial gastrectomy specimens were included. Clinico-radiological data was collected from the medical records of the patients. The histopathologic diagnosis was made on H\&E sections. The exclusion criterion was the biopsies received post neo-adjuvant therapy.

Immunohistochemistry- Her2 status is mainly assessed by immunohistochemistry (IHC) or in situ hybridization (ISH) assays. Both methods can be done on formalin-fixed and paraffin-embedded biopsy tissues or surgical specimens and occasionally cytological samples (cell block 
preparation). ${ }^{6}$ FISH is regarded as the gold standard, however because of its higher cost, need for fluorescence microscopy and time consumption, only equivocal cases are subjected to it. The high concordance between FISH and IHC is reported in the literature supports the use of IHC, the most familiar and readily accommodated method in most laboratories.

In our study, the HER2/neu status was assessed by IHC using a monoclonal anti-HER2/neu-antibody. The Hercep Test scoring system evaluates membranous immunostaining of tumor cells using criteria that include intensity of staining, extent of staining around the cell membrane [complete (basolateral) versus incomplete (lateral) staining] and the percentage of immunoreactive tumor cells. Scores were categorized into four groups $(0,1+$, $2+$ and $3+$ ) depending on intensity of expression. Score $1+$ is faint/barely membranous reactivity in $<10 \%$ of cells, Score $2+$ is weak to moderate complete or basolateral membranous reactivity in $>10 \%$ of cells. Cases having a score of $3+$ are considered to be positive where strong complete or basolateral membranous reactivity in $>10 \%$ of cells is seen. Score of $2+$ considered equivocal further compared with FISH study and cases 0 and $1+$ are negative for Her2/neu expression. ${ }^{7}$

There are two major differences in HER2 staining between breast carcinoma and gastric adenocarcinoma requires modification of immunohistochemical interpretation. First, incomplete membrane staining in a basolateral (or U-shaped) pattern is frequently observed in gastric and gastro-esophageal adenocarcinomas due to the absence of growth receptors on the luminal surface of the cell which is complete in breast carcinoma cases. Second, the tumor heterogeneity with cases having both areas of moderate to strong immunostaining in one type of adenocarcinoma. ${ }^{8,9}$

\section{Principle-}

Immunohistochemistry is a method based on antigen-antibody (Ag-Ab) reactions for identifying substances in tissue which can be made visible microscopically using a suitable label.

The primary antibody binds to specific tissue antigens and the biotinylated secondary $\mathrm{Ab}$ is directed to the primary $\mathrm{Ab}$. The streptavidin/horse radish peroxidase (HRP) is applied then. The streptavidin then binds to the biotin on the secondary antibody and HRP acts as an indicator enzyme. On addition of DAB substrate free oxygen radicals are released which oxidize DAB to a brown colored precipitate. The precipitate gets deposited on the antigen site and can be detected by microscopy.

\section{Results}

The total 54 cases were collected, out of which 19cases are positive for HER2/neu (35.19\%, score $3+), 9$ cases were Equivocal (16.66\%, score 2+), and 26 cases were negative $(48.15 \%$, score 0 and $1)$.

Out of the $19 \mathrm{Her} 2 /$ neu positive cases, 12 cases are male and 7 cases are females $(\mathrm{M}: \mathrm{F}=1.8: 1)$. The age group varied between 20 and 90 years with the commonest age range being 40-50 years. Location wise predominant location was antrum (47.3\%), followed by body (21.3\%), GE junction $(15.7 \%)$, fundus $(10.5 \%)$ and cardia $(5.2 \%)$.

Observation Table 1: Number of cases positive for HER2/neu according to site $(n=19)$

\begin{tabular}{|l|c|c|c|c|c|}
\hline Site & $\begin{array}{c}\text { GE } \\
\text { junction }\end{array}$ & \multicolumn{4}{|c|}{ Stomach } \\
\hline & & Fundus & Cardia & Body & Antrum \\
\hline $\begin{array}{l}\text { Number of Her2/neu } \\
\text { positive cases }\end{array}$ & 3 & 2 & 1 & 4 & 9 \\
\hline$\%$ of cases positive & $15.7 \%$ & $10.5 \%$ & $5.2 \%$ & $21.3 \%$ & $47.3 \%$ \\
\hline
\end{tabular}


Observation Table 2: Scoring pattern of Her2/neu according to the morphological variants of the Gastric Adenocarcinoma and GEJ Adenocarcinoma out of the 54 cases.

\begin{tabular}{|l|c|c|c|c|c|}
\hline $\begin{array}{l}\text { Morphological } \\
\text { variants }\end{array}$ & $\begin{array}{c}\text { Number of } \\
\text { cases }\end{array}$ & $\begin{array}{c}\text { Score } 0 \\
(\text { Negative, } \mathrm{n}=10)\end{array}$ & $\begin{array}{c}\text { Score 1 } \\
\text { (negative, } \mathrm{n}=16)\end{array}$ & $\begin{array}{c}\text { Score 2 } \\
(\text { equivocal, } \mathrm{n}=9)\end{array}$ & $\begin{array}{c}\text { Score 3 } \\
\text { (positive, } \mathrm{n}=19)\end{array}$ \\
\hline $\begin{array}{l}1 . \quad \text { Classical } \\
\text { intestinal }\end{array}$ & 21 & 2 cases $(9.5 \%)$ & 3 cases $(14.28 \%)$ & 4 cases $(19.04 \%)$ & $\begin{array}{c}12 \text { cases } \\
(57.14 \%)\end{array}$ \\
\hline $\begin{array}{l}\text { 2. Diffuse } \\
\text { infiltrative }\end{array}$ & 11 & 3 cases $(27.27 \%)$ & 4 cases $(36.36 \%)$ & 3 cases $(27.27 \%)$ & 1 case $(9.09 \%)$ \\
\hline 3. Mixed & 4 & 3 cases $(75 \%)$ & Nil & 1 case $(25 \%)$ & Nil \\
\hline 4. Papillary & 4 & 1 case $(25 \%)$ & 1 case $(25 \%)$ & Nil & 2 cases $(50 \%)$ \\
\hline 5. Mucinous & 5 & 1 case $(20 \%)$ & 2 cases $(40 \%)$ & 1 case $(20 \%)$ & 1 case $(20 \%)$ \\
\hline 6. Signet ring & 9 & 0 & 6 cases $(66.67 \%)$ & Nil & 3 cases $(33.33 \%)$ \\
\hline
\end{tabular}

Thus, we observed that Her2/ neu positivity was highest in Intestinal type of adenocarcinoma of gastric carcinoma $(57.14 \%)$, followed by papillary adenocarcinoma and signet ring cell and least in Diffuse type of adenocarcinoma. Also strong Her2/neu positivity (3+ score) was significantly more common in the intestinal type of gastric carcinoma $(49 \%)$ than diffuse adenocarcinoma $(4.8 \%)$ where negative score $(0-1)$ was found in $63.6 \%$. It was observed that both in signet ring and papillary carcinoma, the Her2/neu was strongly positive $(33.33 \%$ and $50 \%$ respectively).

Observation Table 3: Positivity for HER2/neu in various histological grades of Gastric Adenocarcinoma. $(\mathrm{n}=19)$

\begin{tabular}{|l|c|c|c|}
\hline Morphological grade & Well differentiated & Moderately differentiated & Poorly differentiated \\
\hline No of cases positive & 9 & 6 & 4 \\
\hline$\%$ of cases positive & $47.36 \%$ & $31.57 \%$ & $21.07 \%$ \\
\hline
\end{tabular}

We observed that most of the Her2 neu positive cases (Score 3+) are well differentiated $(47.36 \%)$

to moderately differentiated

$(31.57 \%)$

adenocarcinomas.

Observation Table 4: Scoring of HER2/neu according to the lymphnode metastasis. $(n=36)$

\begin{tabular}{|l|c|c|c|c|c|}
\hline Score & $\begin{array}{c}\text { Total } \\
\text { number of } \\
\text { cases }\end{array}$ & $\begin{array}{c}\text { Score 0 } \\
\text { (Negative) }\end{array}$ & $\begin{array}{c}\text { Score 1 } \\
\text { (Negative) }\end{array}$ & Score 2 (Equivocal) & $\begin{array}{c}\text { Score 3 } \\
\text { (Positive) }\end{array}$ \\
\hline $\begin{array}{l}\text { No of cases } \\
\text { showing LN } \\
\text { metastasis }\end{array}$ & 36 & $5(13.88 \%)$ & $8(22.22 \%)$ & $6(16.66 \%)$ & $17(47.22 \%)$ \\
\hline
\end{tabular}

Only 36 cases out of 54 showed lymph node metastasis (48\%) and amongst those 17 (47.22\%) showed strong Her2/neu positivity (3+). 


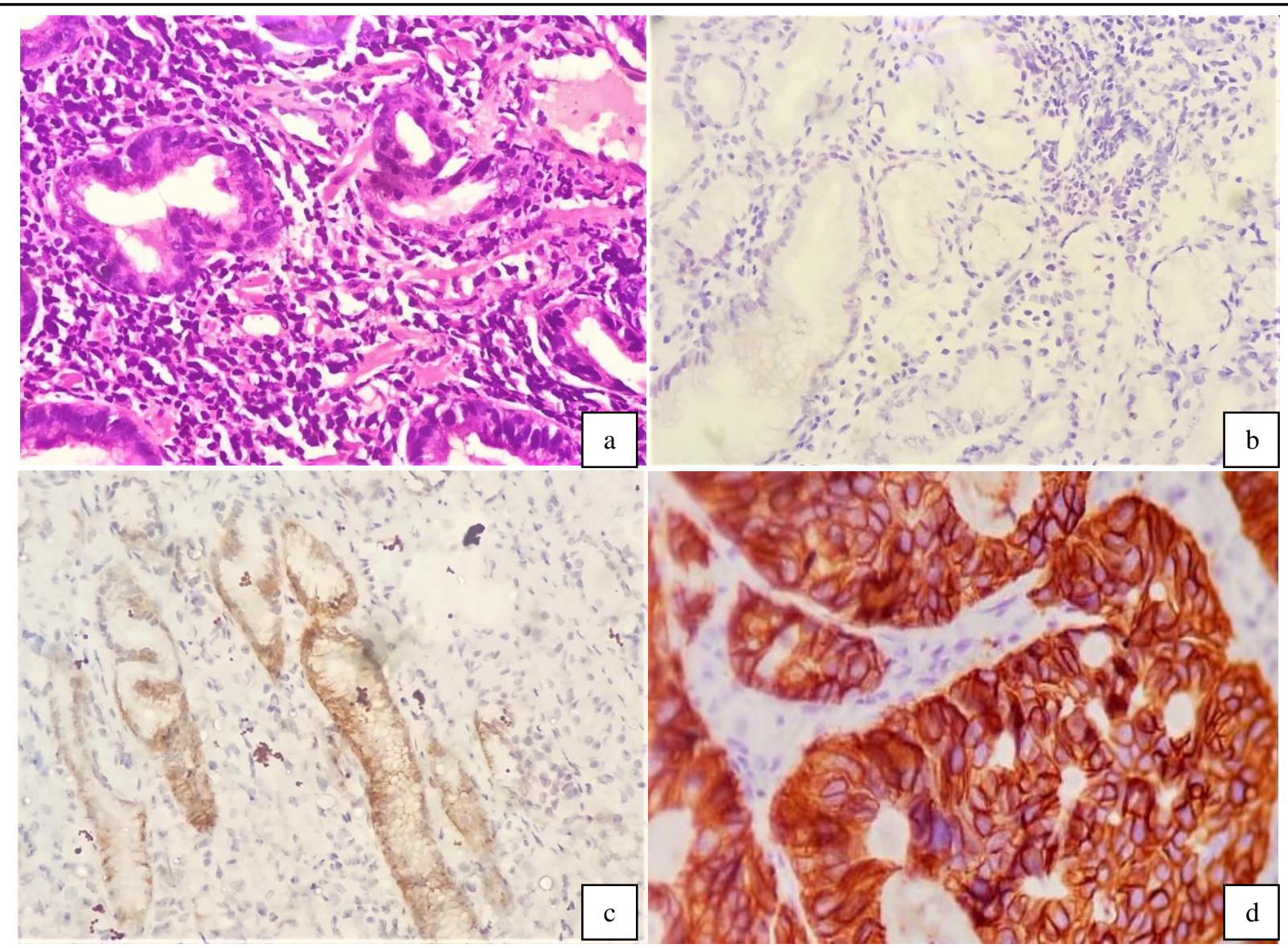

Figure 1: Microphotograph of gastric carcinoma (a) [H\&E] 400X.

Microphotograph of gastric carcinoma showing negative Her2/neu expression (b)[IHC] 400X.

Microphotograph of gastric carcinoma showing equivocal Her2/neu expression (c) [IHC] 400X.

Microphotograph of gastric carcinoma showing strong and complete positive membranous Her2/neu expression (d)[IHC] 400X.

All the strong Her2/neu positive cases of adenocarcinoma were subjected to Transtuzumab therapy which on 1 year follow up showed significant improvement.

\section{Discussion}

The study found that $35.18 \%$ cases of gastric/ gastroesophageal adenocarcinoma showed strong Her2/neu positivity. In 1990s, some series reported a 9\%-38\% of HER2-positive tumors using polyclonal antibodies directed against different domains of HER2 protein. ${ }^{10,11,12}$ In a Japanese series, HER2 over expression by IHC was found in $23 \%$ and gene amplification by FISH in $27 \%$ of 200 resected tumors. ${ }^{13}$ Laboissiere et al. in 2015 found a final HER2-positive status of $10.5 \%$ in his study. ${ }^{14}$ The overall HER2 positivity rate found in the ToGA study was 810 of 3,665 patients $(22.1 \%){ }^{5}$

In our study, we found that the commonest histologic variant with Her2/neu positivity was
Intestinal type (57.14\%) and the least common is diffuse type $(9.09 \%)$. Lordick et al. in 2007observed $341(22 \%)$ of 1527 tumors were HER2 positive, differed according to histological subtype (intestinal 34\%, diffuse 6\%, mixed $20 \%){ }^{15}$ García-Carbonero $\mathrm{R}$ et al. observed a higher rate of HER2 overexpression in intestinal than in diffuse type (16\% vs $7 \%) .{ }^{16}$ Intestinal-type cancers also exhibited higher rates of HER2 amplification than did diffuse-type cancers ( $\mathrm{P}<$ $0.05)$ in the Korean study. ${ }^{17}$ In the ToGA trial, HER2 positivity differed significantly by histological subtype (intestinal 34\%, diffuse 6\%, mixed $20 \%)^{5}$

Most of the gastric carcinomas arising in the antrum of stomach showed strong Her2/neu 
positivity $3+$ score $(47.3 \%)$ in our study. However, Tanner et al. ${ }^{18}$ found HER2 positivity were higher in GE junction than in gastric tumors (24\% vs 12\%). Most of the Her2/neu positive cases in our study are well to moderately differentiated $(47.36 \%$ to $31.57 \%)$ when compared to Ling Shah et al. ${ }^{19}$ which also showed the similar result i.e. a correlation of HER2positivity with well or moderately differentiated carcinomas was found with $\mathrm{p}<0.01 .89 .47 \%$ of Score 3+ Her2/neu showed lymph node metastasis in our study. Laboissiere et al. found IHC 3+ tumor showed lymphovascular invasion and they were all diagnosed at an advanced stage of disease, mainly in thepT3 category $(76.9 \%){ }^{14}$ $84.6 \%$ of cases were positive for lymph node metastasis, with an average of 7.5 positive nodes per case.

\section{Conclusion}

Gastric cancer is the third leading cause of cancer mortality in the world. The prevalence of gastric cancer is high especially in the Eastern part of India and is diagnosed when the tumor is at an unresectable stage. In this setting, systemic chemotherapy is the main treatment option. Although many single agents and combinations are active in metastatic disease, there is no internationally accepted protocol of treatment and survival remains poor. Therefore, new therapeutic strategies are needed. The results of these studies will contribute to a better knowledge of the efficacy and tolerance of Trastuzumab-based therapy in HER2-positive gastric or GEJ cancers. We found there is a shift in the incidence of Gastric carcinoma from an older age group to a younger age group in Southern part of Odisha. Though strong Her2/neu positivity was observed in well differentiated type $(47.36 \%)$, lymphnodal metastasis (stage 3) disease showed higher incidence of strong Her2/neu (score $3+$ ) positivity. Thus the targeted therapy is highly recommended in Her2/neu positive (score $3+$ ) cases which is effective not only for the primary disease but also in lymph node and distant metastasis to further reduce the morbidity and mortality of the patients.

\section{References}

1. Ferlay J, Soerjomataram I, Dikshit R, Eser $\mathrm{S}$, Mathers C, Rebelo M, et al. Cancer incidence and mortality worldwide: sources, methods and major patterns in GLOBOCAN 2012. Int J Cancer 2015; 136:359-86.

2. Akiyama T, Sudo C, Ogawara H, Toyoshima K, Yamamoto T. The product of the human c-erbB-2 gene: a 185kilodalton glycoprotein with tyrosine kinase activity. Science 1986; 232:1644-6.

3. Slamon DJ, Clark GM, Wong SG, Levin WJ, Ullrich A, McGuire WL. Human breast cancer: correlation of relapse and survival with amplification of the HER2/neu oncogene. Science 1987; 235: $177-$ 82.

4. Yan M, Schwaederle M, Arguello D, Millis SZ, Gatalica Z, Kurzrock R. HER2 expression status in diverse cancers: review of results from 37,992 patients. Cancer Metastasis Rev 2015; 34: 157-64.

5. Bang YJ, Van Cutsem E, Feyereislova A, Chung HC, Shen L, Sawaki A, et al. Trastuzumab in combination with chemotherapy versus chemotherapy alone for treatment of HER2-positive advanced gastric or gastro-oesophageal junction cancer (ToGA): a phase 3, open-label, randomised controlled trial. Lancet 2010; 376:687-97.

6. Wong DD, de Boer WB, Platten MA, Jo VY, Cibas ES, Kumarasinghe MP. HER2 testing in malignant effusions of metastatic gastric carcinoma: is it feasible? Diagn Cytopathol 2015; 43: 80-5.

7. Hofmann M, Stoss O, Shi D, Büttner R, van de Vijver $M$, Kim $W$, et al. Assessment of a HER2 scoring system for gastric cancer: results from a validation study. Histopathology 2008;52:797-805. 
8. Rüschoff J, Dietel M, Baretton $\mathrm{G}$, Arbogast S, Walch A, Monges G, et al. HER2 diagnostics in gastric cancerguideline validation and development of standardized immunohistochemical testing. Virchows Arch 2010; 457: 299307.

9. Albarello L, Pecciarini L, Doglioni C. HER2 testing in gastric cancer. AdvAnatPathol 2011; 18: 53-9.

10. Yonemura Y, Ninomiya I, Yamaguchi A, Fushida S, Kiimini H, Ohoyama S, et al. Evaluation of immunoreactivity for erbB-2 protein as a marker of poor short-term prognosis in gastric cancer. Cancer Res 1991;51:1034-8.

11. Ishida T, Tsujisaki M, Hanzawa Y,Hirakawa T, Hinoda Y, Imai K, et al. Significance of erbB-2 gene product as a target molecule for cancer therapy, Scand J Immunol 1994;39: 459-66

12. Tokunaga A, Onda M, Okuda T, Teramoto T, Fujita I, Mizutani T, et al. Clinical significance of epidermal growth factor (EGF), EGF receptor and c-erbB-2 in human gastric cancer. Cancer 1995;75:1418-25.

13. Yano T, Ochiai A, Doi T. Expression of HER2 in gastric cancer: comparison between protein expression and gene amplification using a new commercial kit. J ClinOncol 2004;22:14.

14. Laboissiere RS, Buzelin MA, Balabram D,Brot MD, Nunes CB, Rocha RM et al. Association between HER2 status in gastric cancer and clinicopathological features: a retrospective study using whole-tissue sections. BMC Gastroenterol 2015;15:157.

15. Lordick F, Bang YJ, Kang YK, Otero Reyes D, Manikhas GM, Shen L, et al. HER2-positive advanced gastric cancer: similar HER2-positivity levels to breast cancer. Eur J Cancer2007;5:272.
16. Gravalos, C., Jimeno A. HER2 in gastric cancer: a new prognostic factor and a novel therapeutic target. Ann Oncol2008;19:1523-1529.

17. Park DI, Yun JW, Park JH, et al. HER$2 /$ neu amplification is an independent prognostic factor in gastric cancer, Dig Dis Sci2006; 51:1371-9.

18. Tanner M, Hollmen M, Junttila TT, et al. Amplification of HER-2 in gastric carcinoma: association with topoisomerase IIa gene amplification, intestinal type, poor prognosis and sensitivity to trastuzumab, Ann Oncol 2005;16: 273-8.

19. Shan L, Ying J, Lu N. HER2 expression and relevant clinicopathological features in gastric and gastroesophageal junction adenocarcinoma in a Chinese population. Diagn Pathol2013; 8:76. 